that in a few years more he might again require its repetition. The Baron immediately wrote in reply, that he would comply with my wishes, and came accordingly to Nottingham in the most ready and liberal manner. He examined the patient, and foretold the nature and probable size of the calculus. On the 12th January he performed the operation before a large assemblage of medical practitioners of this town and neighbourhood, and afterwards gave a demonstration of the various steps of the operation, and the means by which he brought it to its present state of perfection. The calculus was twice seized and broken by the percuteur, and from beginning to end the operation did not occupy more than from four to five minutes' time. The patient expressed surprise on being told it was finished, and moved from the table with much less uneasiness and pain than he had felt in placing himself there. Immediately on reaching his bed he voided, along with the warm water which had been introduced into the bladder prior to the use of the percuten', a considerable portion of the detritus and some small fragments of the stone. He had a better night than he had passed for many weeks; indeed he now experienced no pain, except what was prorluced by the occasional passage along the urethra of some angular portions of stone. The urine voided that night and the following day was slightly tinged with blood, and contained about its usual quantity of ropy tenacious mucus, which for a long time past had been voided in very large quantities. The next day he passed a very large fragment, and by night the urine was nearly freed from the mucous deposit. On the 16 th (4th day) the urine was perfectly clear. He complained of a prickling and itching sensation within the anus, and on sitring down, a pain striking to the glans; but he passed no more fragments, and those collected amounted to half a drachn in weight. $\mathrm{U}_{\mathrm{p}}$ to this time he experienced more or less of these sensations, and on this day he felt a return of his former symptoms, but in a very mitigated degree. I thought it very possible that a fragment of the stone was resting on the neck of the bladder, or had entered the prostatic portion of the urethra, which, on the introduction of the catheter, I found to be the case; I pushed it back into the bladder, and entirely relieved him of his pain. On the 20th he complained of a sensation, as if he wanted to part with something from the bladder, which he could not effect, but he had little or no pain. On the 25th the Baron came again to Nottingham, and by a second operation immediately succeedẹd in seizing and break- ing down two remaining fragments, the detritus of which the patient passed. Since that time he has been entirely rid of every morbid sensation, and has continued so up to the present moment. His urine remains perfectly free from mucous deposit, and he has passed neither broken fragments nor renal calculi since the evening of the last operation. The interest excited by this case arises out of the circumstances of this man having undergone the lateral operation for stone, and subsequently that of lithotripsy. On the comparative merits of these two operations, I will offer no comments of my own, but leave the patient to speak for himself. He said, "Although relieved from the more urgent symptoms immediately after the former operation, still I suffered more or less from the smarting of the wound, and the continued flow of urine through it; and the pain I experienced at the time was more than I could well bear. In the opcration performed by the Baron, the sensation I experienced was scarcely to be called painful; and except from the passage of the broken pieces of stone, I had no subsequent inconvenience or uneasy sensation. And ever since the second operation, I have been entirely relieved from all my former painful feelings."

It is evident, that had the Baron been at Nottingham when the patient experienced the first uneasiness from the presence of the fragments, he would have been entirely cured of the disease on the fourth day, when the second operation would very probably have been performed. I am, Sir, your obedient servant,

Henry Oldznow.

Nottingham, March 5th, 1833.

CASE VII.-CURE OF STONE BV LITHOTRIPSY AT THE DERBYSIIRE GENERAL HOSPITAL.

James Warren, aged 28, had stone in the bladder three yenrs. When he had suffered from it about two years, he was admitted into the Birmingham Hospital to undergo the operation of lithotripsy; he remained there upwards of two months, but the surgeon under whose care he was placed, did not succeed in seizing the stone; he consequently left the hospital without being relieved, not choosing to undergo the operation of lithotomy.

On the 8th of April in this year, he came into the Derbyshire General Hospital under my care, to be examined by Baron Heurteloup, and to be operated upon if a proper case. He had walked fourteen miles on the day in question, but having rested several hours, and the bladder not 
appearing in an irritable condition, the Baron determined to examine him, and to operate if he found the case such as he thought proper for lithotripsy.

At three o'clock p.m., the petient having been placed upon the operation table, the Baron injected water into the bladder through his hollow sound. He next ascertained that a stone nearly an inch in length, and almost as thick, was present. Having withdrawn the sound, he introduced his percuieur, with which he seized the stone, and immediately broke it down. He then examined, to ascertain whether any large fragmerits remained which required to be crushed, and he discovered two, each of which he broke down. The breaking of the stone and the two fragments, occupied exactly two minutes. The patient did not experience much pain from the operation, nor did he afterwards suffer from any unpleasant symptom. He parted with a considerable quantity of minute fragments during four or five days after the operation, when he was perfectly cured. I made the most careful examination to ascertain whether any fragment remained, but could not discover any. He has remained free from all appearance of stone ever since: it is now June 18th, 1833. There were nearly one hundred members of the medical profession present at the operation, all of whom were highly delighted with the skill of the Baron and the success of the operation.

(Signed)

Dovglas Fox, One of the Surgeons of the Derbyshixe General Hospital.

Derby, June 12th, 1833.

\section{CAST OF}

\section{ACUTE LARYNGITIS}

SUCCESSFULLY TREATED,

By Pye Henry Chavasse, Esq., Surgeon, Birmingham.

If there be any disease that requires more than an ordinary share of prompt attention, it is acute laryngitis, a disease which sometimes runs its course in a few hours, either to end in recovery or in death, and a case of which I had an opportunity of witnessing a few months ago. As acute laryngitis is rather of rare occurrence, an account of the case may not prove altogether unacceptable to sorne of the numerous readers of The Lancet.

CAse.-Feb. 22nd, 1833. M. S., a servant-maid, ætat. 20 , and of sanguineous temperament, was taken ill yesterday.

No. 517.
This morning I saw her for the first time, and found her labouring under the following symptoms:- Respiration loud and rough; cough clanging; she could only speak in a hoarse whisper, and then only with the greatest difficulty; great dyspnoa, which at times was aggravated to a fearful degree; her face was bloated, her eyelids were swollen, and during the superadded paroxysms of difficulty of breathing, her face was pallid and ghastly, and her lips were blue. There was extreme tenderness on pressing over the larynx, and the pulse was hard and rapid; the tongue was white and furred; the secretions were checked; the skin was dry; the bowels were costive; the urine was scanty and high-coloured; there was great thirst; and the countenance depicted peculiar anxiety and distress.

Treatment.-I immediately bled her to thirty ounces, as I could not produce fainting till that quantity had been abstracted. She had not lost more than half that quantity before a decided improvement took. place: the breathing became less difficult; she was less loud and hoarse; the countenance, before indicative of the greatest distress, now brightened up ; the eyelids, before humid and swolien, regained nearly their usual appearance; the pulse, before hard and rapid, became soft and less frequent. It was most gratifying to watch the rapid changes which the loss of blood occasioned as it trickled from the arm. After the bleeding, I ordered eighteen leeches to be applied to the throat; a purging enema to be administered immediately, and followed up in the course of an hour if necessary. I then prescribed the following medicine :-

Bo Hyd.submur. 3̧ss;

Pulv. opii gr. ij;

Confec. rose q. s. Pil. vj capiat $\mathbf{j}$, tertiis horis, cum cochl. ij amp. mist. sequenti.

Bo Liq.ammon. acet. 3ิiij;

Mist. camphor. $\frac{3}{\mathrm{v}}$. Misce. Toast and water to quench the thirst.

Nine o'clock p.m. Breathing nearly natural; the patient now able to speak aloud; hoarseness very much diminished; tenderness over the larynx no longer exists; pulse soft, and not frequent; skin moist; bowels freely opened. The blood which was drawn in the morning is very much buffed and cupped. Pergat.

Suffice it to say, that in a few days the patient was quite convalescent.

Birmingham, July 22nd, 1833. 